\title{
Combining anticoagulation and antiplatelet drugs in coronary artery disease
}

\section{SUMMARY}

Most patients with stable coronary disease are managed with a single antiplatelet drug. For those who require anticoagulation, an antiplatelet drug may not be required.

Antiplatelet therapy for patients who have an acute coronary syndrome helps to prevent future cardiovascular events. This benefit can be increased by using two antiplatelet drugs.

The choice of drug is determined for each individual patient. Factors to consider include whether the patient had a stent inserted, the risk of bleeding and whether they have another indication for anticoagulation.

For patients without a stent, aspirin can be combined with a P2Y ${ }_{12}$ antagonist for up to 12 months. Only one antiplatelet drug is recommended if the patient also needs long-term anticoagulation.

Following stent insertion, patients with an indication for anticoagulation have been treated with two antiplatelet drugs and an anticoagulant. Recent research suggests that selected patients may be managed with one antiplatelet drug and an anticoagulant. After 12 months it may be possible to manage the patients with an anticoagulant alone.

\section{Introduction}

Antiplatelet drugs play an important role in the secondary prevention of atherosclerotic coronary disease. They reduce the relative risk of subsequent vascular events (non-fatal myocardial infarction, nonfatal stroke and vascular death) by approximately

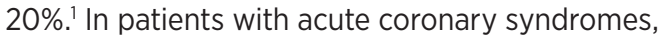
with or without percutaneous intervention, adding a second antiplatelet drug further reduces ischaemic events, albeit with a small increased risk of bleeding. ${ }^{2}$ Often aspirin is used in combination with an antagonist of the $\mathrm{P} 2 \mathrm{Y}_{12}$ receptor, such as clopidogrel (see Fig. 1).

A significant proportion of patients with coronary artery disease have other conditions that require oral anticoagulants. These include atrial fibrillation, left ventricular thrombus or aneurysm, prosthetic heart valve, and venous thromboembolism. While there is evidence that oral anticoagulants reduce ischaemic events in patients with coronary artery disease, they are not used as sole therapy in patients with acute coronary syndromes. Following percutaneous coronary interventions, antiplatelet drugs are required to prevent in-stent thrombosis. In-stent thrombosis has a mortality of $50-70 \%,{ }^{3}$ so the use of one or two antiplatelet drugs together with an anticoagulant is often required. However, such combinations increase the risk of bleeding. Overall, treatment must be individualised with a careful assessment of the risks of thrombosis and bleeding to find the optimal balance between harm and benefit.

\section{Risk assessment}

There are a number of scoring systems that predict the risk of further coronary events after acute coronary syndrome, including the GRACE and TIMI scores. ${ }^{4}$ There are also scoring systems that predict stroke in patients with atrial fibrillation, the commonest of which is the $\mathrm{CHA}_{2} \mathrm{DS}_{2}$ Vasc score (Table 1). ${ }^{5}$

The assessment of bleeding risk is more difficult. The HAS-BLED score ${ }^{5}$ (Table 2) is a commonly used bleeding risk score which includes risk factors for bleeding during warfarin therapy. It is not validated for patients receiving other oral anticoagulants. The HAS-BLED score's greatest use is in identifying modifiable risk factors for bleeding that may be improved, rather than identifying patients who should not be anticoagulated. Additional scores are in development - the GARFIELD-AF score ${ }^{6}$ gives one-year rates of death, stroke and bleeding in atrial fibrillation and, while very promising, it does require further validation.

\section{Anticoagulation in acute coronary syndrome without percutaneous coronary intervention}

After an acute coronary syndrome, patients remain at risk for recurrent cardiovascular events despite standard medical therapy. This risk may be related
Jyotsna Janardan General physician

\section{Harry Gibbs}

Program director, Outpatients, and Deputy director, General Medicine

Alfred Health, Melbourne

\section{Keywords}

acute coronary syndrome anticoagulants antiplatelets, coronary artery disease

Aust Prescr 2018:41:111-5 https://doi.org/10.18773/ austprescr.2018.039 


\section{Fig. 1 Treatment pathways after acute coronary syndrome}

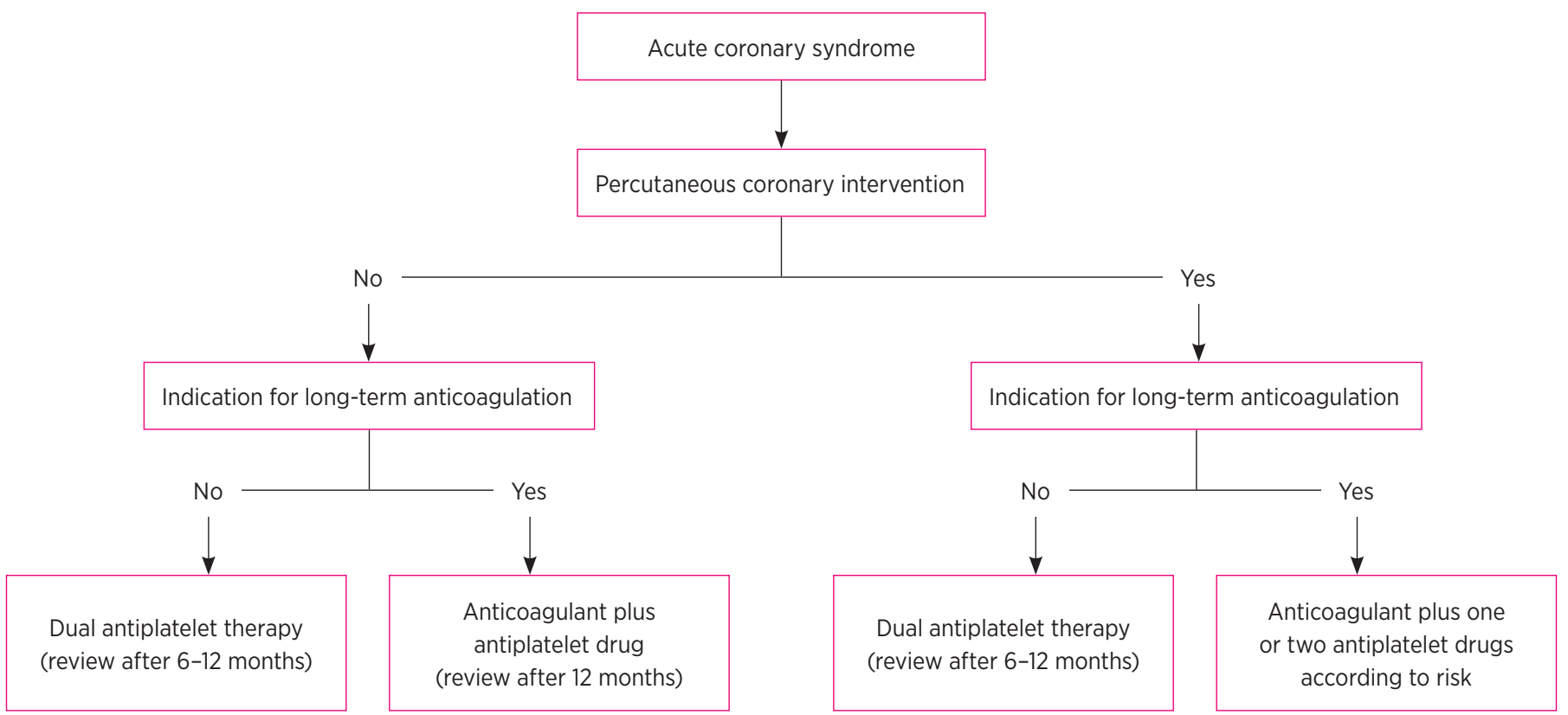

\section{Table 1 CHA DS $_{2}$ Vasc score}

\section{Criteria}

Score (maximum 9)

Congestive heart failure

Hypertension

Age $\geq 75$ years

Diabetes mellitus

Stroke/transient ischaemic attack/thromboembolism

Vascular disease (previous myocardial infarction, peripheral artery disease or aortic plaque)

Age 65-74 years

Sex female

Total score calculates risk of stroke

0 = low risk $\quad 1=$ moderate risk $\quad>1=$ high risk

\section{Table 2 HAS-BLED score}

\begin{tabular}{lr} 
Criteria & Score \\
\hline $\begin{array}{l}\text { Hypertension (systolic blood pressure } \\
>160 \mathrm{mmHg})\end{array}$ & 1 \\
Abnormal liver or renal function (1 point each) & 1 \\
Stroke & 1 \\
Bleeding history & 1 \\
Labile INRs & 1 \\
Elderly (age $>65$ years) & 1 \\
$\begin{array}{l}\text { Drugs/alcohol that promote bleeding } \\
(1 \text { point each) }\end{array}$ & 1 \\
\hline
\end{tabular}

A score of 3 or more indicates an increased one-year bleed risk on anticoagulation sufficient to justify caution or more regular review. to an excess of thrombin production that persists beyond the acute presentation. ${ }^{7}$ All patients require antiplatelet drugs, but the regimen is influenced by any need for anticoagulation.

\section{Patients without a pre-existing indication for anticoagulation}

The results of several studies indicate that therapeutic anticoagulation using oral anticoagulants is not routinely recommended for patients with acute coronary syndromes who do not have another indication for anticoagulant therapy.
Multiple randomised studies have assessed the outcomes of warfarin and aspirin versus aspirin alone in acute coronary syndromes. A meta-analysis of 25307 patients showed that in studies of warfarin with a target INR of 2-3, the addition of aspirin was associated with a significant reduction of major adverse events (all-cause death, non-fatal myocardial infarction, and non-fatal thromboembolic stroke) but with an increased risk of major bleeding. ${ }^{8}$ When all trials, irrespective of INR control, were included there was no reduction in cardiac events, but there was a significant increase in major bleeding. Widespread use 
of long-term warfarin in these patients is therefore not recommended.

More recent trials have studied a possible role for the newer oral anticoagulants. Rivaroxaban ${ }^{9}$ and apixaban ${ }^{10}$ have both been studied in patients with recent acute coronary syndrome. The doses of rivaroxaban studied were low (2.5 mg twice daily and $5 \mathrm{mg}$ twice daily) and these doses are not currently available in Australia. In combination with aspirin and another antiplatelet drug, the low doses of rivaroxaban reduced the composite of death from cardiovascular causes, myocardial infarction, or stroke compared to placebo. There was an increase in intracranial haemorrhage and major bleeding not related to coronary artery bypass grafting, without a significant increase in fatal bleeding with rivaroxaban. Apixaban was studied in a standard dose (5 mg twice daily) in combination with aspirin or dual antiplatelet therapy. This trial was stopped early due to a significant increase in the rate of major bleeding in the apixaban group, compared to placebo. There was no reduction of cardiac events with apixaban. ${ }^{10}$

The European Society of Cardiology guidelines in 2015 suggested that rivaroxaban $2.5 \mathrm{mg}$ twice daily might be considered in combination with aspirin and clopidogrel for non-ST-elevation myocardial infarction in patients who have high ischaemic risks but low bleeding risks. Caution is needed in patients more than 75 years of age or less than $60 \mathrm{~kg}$ bodyweight."

\section{Patients with a pre-existing indication for anticoagulation}

For patients with acute coronary syndrome who have been managed without intracoronary stenting (by medical management, fibrinolytic therapy, or coronary artery bypass graft surgery), and who also have another indication for chronic anticoagulation (e.g. atrial fibrillation), it is usual to use a single antiplatelet drug and an oral anticoagulant. After one year, if the patient has had no further coronary events, it is reasonable to stop the antiplatelet drug and continue the oral anticoagulant. The strength of evidence for this recommendation is low, but it is common practice.

There are no randomised trials comparing an oral anticoagulant in combination with a single antiplatelet drug to an oral anticoagulant and dual antiplatelet therapy in patients without coronary stents. A brief period of oral anticoagulants and dual antiplatelet therapy for 1-3 months is reasonable in selected patients who are at low risk of bleeding, but have a particularly high risk of recurrent ischaemic events.

\section{Anticoagulation after coronary stent insertion}

Nowadays patients with acute coronary syndromes are often managed with a percutaneous coronary intervention, predominantly by intracoronary stent placement. Long-term antiplatelet therapy is required to prevent stent thrombosis, but some patients may also require anticoagulation (see Fig. 2).

\section{Fig. 2 Suggested approach for patients requiring chronic anticoagulation after intracoronary stenting}

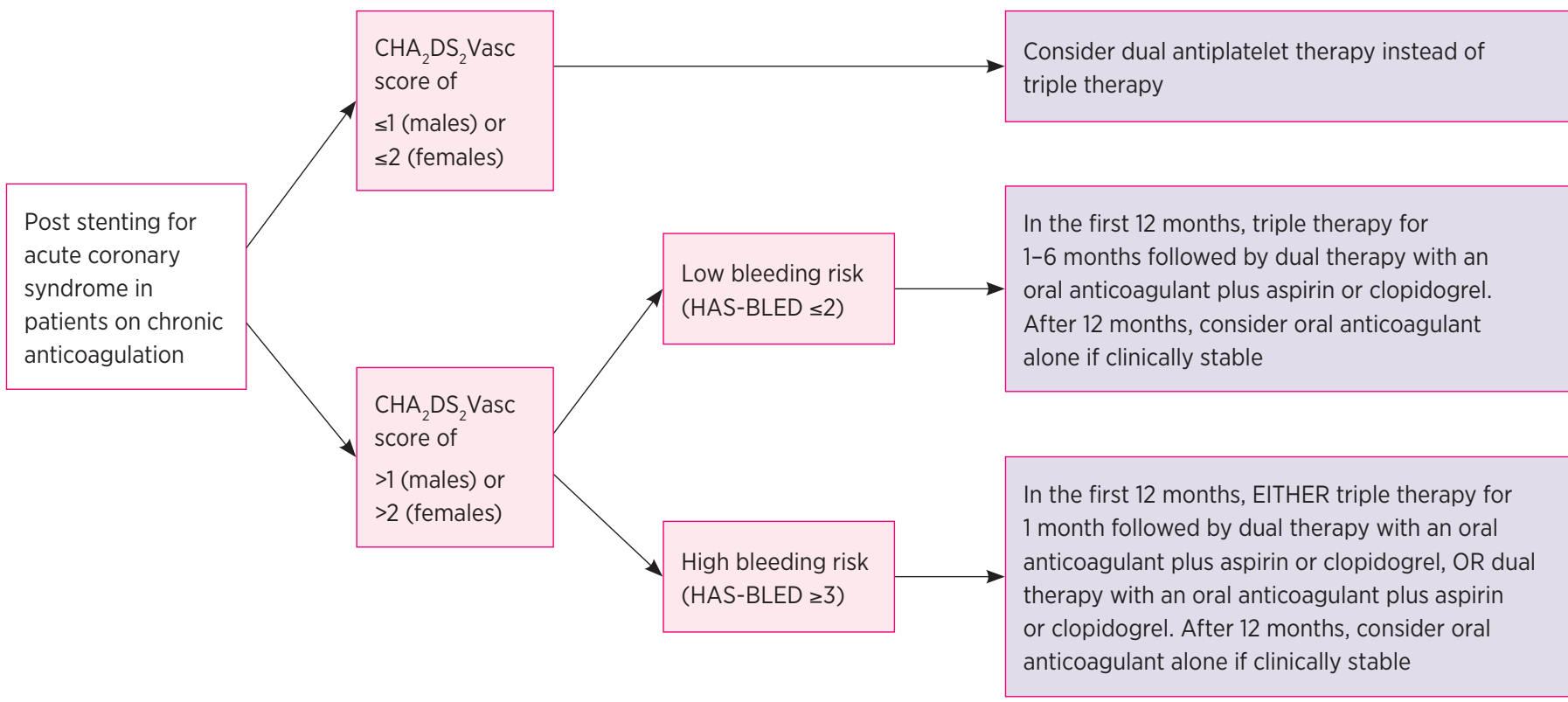




\section{Patients with a pre-existing indication for anticoagulation}

About $5-10 \%$ of the patients scheduled for coronary artery stenting are already taking oral anticoagulants, usually for atrial fibrillation. ${ }^{2}$ Until recently, the suggested approach for these patients was to take aspirin, clopidogrel and an oral anticoagulant (triple therapy) for 1-6 months following the insertion of a drug-eluting stent, then stop one of the antiplatelet drugs. $\mathrm{P} 2 \mathrm{Y}_{12}$ antagonists other than clopidogrel (ticagrelor and prasugrel) are not recommended for triple therapy due to higher bleeding rates.

The WOEST study ${ }^{13}$ was the first trial comparing dual versus triple therapy after insertion of coronary stents. Patients who were receiving long-term oral anticoagulants and undergoing percutaneous intervention were randomised to warfarin plus clopidogrel alone (dual therapy) or warfarin plus clopidogrel and aspirin (triple therapy). The treatment was for at least one month following bare-metal stenting and for 12 months following drug-eluting stenting. The primary outcome of bleeding was significantly higher in the triple therapy group (44.4\% vs 19.4\%). The combined secondary end point of death (myocardial infarction, stroke, target-vessel revascularisation, and stent thrombosis) was lower with dual therapy (11.1\% vs $17.6 \%$ ).

There is considerable interest in optimising strategies following coronary stent placement using the non-vitamin $\mathrm{K}$ oral anticoagulants, with studies of rivaroxaban and dabigatran now available.

The PIONEER AF-PCI trial ${ }^{14}$ studied 2124 patients with non-valvular atrial fibrillation who had undergone percutaneous coronary intervention with stenting to one of three antithrombotic regimens. Patients were randomised in a 1:1:1 ratio to:

- low-dose rivaroxaban (15 mg daily) plus a P2Y 12 inhibitor for 12 months

- $\quad$ very-low-dose rivaroxaban (2.5 mg twice daily) plus dual antiplatelet therapy

- dose-adjusted warfarin plus dual antiplatelet therapy.

The primary outcome of clinically significant bleeding occurred less commonly in the two groups receiving rivaroxaban. There was no significant difference in the incidence of ischaemic cardiovascular events in the three groups, but the trial was underpowered for this end point so firm conclusions about efficacy cannot be drawn. ${ }^{10}$ Many clinicians are concerned that low-dose rivaroxaban may not provide sufficient protection against stroke in patients with atrial fibrillation.
The RE-DUAL trial ${ }^{15}$ involved 2725 patients with atrial fibrillation who had undergone percutaneous intervention. They were randomised to:

- $\quad$ triple therapy with warfarin plus a P2Y ${ }_{12}$ inhibitor (clopidogrel or ticagrelor) and aspirin (for 1-3 months)

- dual therapy with dabigatran (110 mg or $150 \mathrm{mg}$ twice daily) plus a $\mathrm{P}_{2} \mathrm{Y}_{12}$ inhibitor (clopidogrel or ticagrelor).

Both dabigatran groups had a significantly lower incidence of major or clinically relevant non-major bleeding. Dual therapy was non-inferior to triple therapy with warfarin for thromboembolic events.

Recruitment is currently underway for the AUGUSTUS trial comparing apixaban and warfarin in patients with atrial fibrillation undergoing percutaneous intervention. The primary outcome will be the rate of major bleeding.

The trials appear to show that dual therapy (oral anticoagulant plus one antiplatelet drug) is a reasonable option after stent insertion for patients with an indication for anticoagulation, particularly in those patients with a high bleeding risk.

\section{Patients without a pre-existing indication for anticoagulation}

There have been a number of studies examining the role of warfarin compared to antiplatelet drugs to prevent stent thrombosis in patients without another indication for oral anticoagulants. The largest of these showed a higher rate of stent thrombosis in patients receiving either aspirin alone or warfarin and aspirin compared to dual antiplatelet therapy with aspirin and ticlopidine. ${ }^{16}$ Based on this and on other trials with concordant results, dual antiplatelet therapy is recommended to prevent stent thrombosis following stent placement in the absence of another indication for oral anticoagulation. It should be noted that these trials used early-generation stents that were associated with a higher rate of stent thrombosis than contemporary stents.

\section{Anticoagulation in stable coronary artery disease}

Stable coronary artery disease includes patients who are asymptomatic following an acute coronary syndrome, patients with transient episodes of angina or demonstrable ischaemia precipitated by a reversible mismatch of myocardial supply and demand, and asymptomatic patients with known atherosclerotic disease confirmed by invasive or CT coronary angiography. It is common practice to use a single antiplatelet drug in these patients, but 5-10\% will have recurrent events each year. ${ }^{17}$ 
The role of oral anticoagulants in secondary prevention was recently explored in the COMPASS trial. ${ }^{18}$ This trial randomly assigned 27395 participants with stable atherosclerotic vascular disease to receive rivaroxaban (2.5 mg twice daily) plus aspirin, rivaroxaban alone (5 mg twice daily), or aspirin alone. The incidence of the primary outcome (composite of cardiovascular death, stroke, or myocardial infarction) was lower with rivaroxaban $2.5 \mathrm{mg}$ plus aspirin compared with aspirin alone (4.1\% vs $5.4 \%$, hazard ratio (HR) 0.76, 95\% confidence interval $(\mathrm{Cl})$ $0.66-0.86, P<0.001)$ but with more major bleeding events (3.1\% vs $1.9 \%$, HR 1.70, 95\% Cl 1.4-2.05). While it is not yet used in routine practice for patients with stable coronary artery disease, oral anticoagulation might have a role in selected patients with a high risk of ischaemic events but a low bleeding risk.

The optimal long-term antithrombotic treatment of patients with atrial fibrillation and stable coronary artery disease is unresolved. It is common practice to add antiplatelet therapy to anticoagulation. However, a retrospective observational study reported that the addition of an antiplatelet drug to warfarin therapy is not associated with a reduction in the risk of recurrent coronary events or thromboembolism. The risk of bleeding was increased significantly when aspirin (HR 1.5, 95\% Cl 1.23-1.82) or clopidogrel (HR 1.84, $95 \% \mathrm{Cl} 1.11-3.06$ ) was added to warfarin..$^{19}$

For patients with atrial fibrillation who need anticoagulation and have either asymptomatic stable coronary artery disease or a high risk of bleeding, it would be reasonable to use oral anticoagulants alone.

\section{Conclusion}

Recent trials have explored the use of oral anticoagulants in patients with coronary artery disease. While there is an expanding role for oral anticoagulants with or without antiplatelet drugs, the bleeding risk is significant. Treatment must be tailored to the patient after careful consideration of harm versus benefit, and a clear plan conveyed to patients and their entire health team. $<$

\section{Conflict of interest: none declared}

\section{REFERENCES}

1. Antithrombotic Trialists' Collaboration. Collaborative meta-analysis of randomised trials of antiplatelet therapy for prevention of death, myocardial infarction, and stroke in high risk patients. BMJ 2002;324:71-86. https://doi.org/10.1136/bmj.324.7329.71

2. Yusuf S, Zhao F, Mehta SR, Chrolavicius S, Tognoni G, Fox KK, et al; Clopidogrel in Unstable Angina to Prevent Recurrent Events Trial Investigators. Effects of clopidogrel in addition to aspirin in patients with acute coronary syndromes without ST-segment elevation. N Engl J Med 2001;345:494-502. https://doi.org/10.1056/NEJMoa010746

3. Valgimigli M, Bueno H, Byrne RA, Collet JP, Costa F, Jeppsson A, et al; ESC Scientific Document Group; ESC Committee for Practice Guidelines (CPG); ESC National Cardiac Societies. 2017 ESC focused update on dual antiplatelet therapy in coronary artery disease developed in collaboration with EACTS: The Task Force for dual antiplatelet therapy in coronary artery disease of the European Society of Cardiology (ESC) and of the European Association for Cardio-Thoracic Surgery (EACTS). Eur Heart J 2018;39:213-60.

https://doi.org/10.1093/eurheartj/ehx419

4. de Araújo Gonçalves P, Ferreira J, Aguiar C, Seabra-Gomes R. TIMI, PURSUIT, and GRACE risk scores: sustained prognostic value and interaction with revascularization in NSTE-ACS. Eur Heart J 2005;26:865-72. https://doi.org/ 10.1093/eurheartj/ehi187

5. Lane DA, Lip GY. Use of the CHA DS -VASC and HAS-BLED scores to aid decision making for thromboprophylaxis in nonvalvular atrial fibrillation. Circulation 2012;126:860-5. https://doi.org/10.1161/CIRCULATIONAHA.111.06006

6. Fox KAA, Lucas JE, Pieper KS, Bassand JP, Camm AJ, Fitzmaurice DA, et al: GARFIELD-AF Investigators. Improved risk stratification of patients with atrial fibrillation: an integrated GARFIELD-AF tool for the prediction of mortality, stroke and bleed in patients with and without anticoagulation. BMJ Open 2017;7:e017157. https://doi.org/10.1136/bmjopen-2017-017157

7. Merlini PA, Bauer KA, Oltrona L, Ardissino D, Cattaneo M, Belli C, et al. Persistent activation of coagulation mechanism in unstable angina and myocardial infarction. Circulation 1994;90:61-8. https://doi.org/10.1161/ 01.CIR.90.1.61

8. Andreotti F, Testa L, Biondi-Zoccai GG, Crea F. Aspirin plus warfarin compared to aspirin alone after acute coronary syndromes: an updated and comprehensive meta-analysis of 25,307 patients. Eur Heart J 2006;27:519-26. https://doi.org/10.1093/eurheartj/ehi485

9. Mega JL, Braunwald E, Wiviott SD, Bassand JP, Bhatt DL, Bode C, et al; ATLAS ACS 2-TIMI 51 Investigators. Rivaroxaban in patients with a recent acute coronary syndrome. N Engl J Med 2012;366:9-19. https://doi.org/10.1056/ NEJMoal112277
10. Alexander JH, Lopes RD, James S, Kilaru R, He Y, Mohan P, et al; APPRAISE-2 Investigators. Apixaban with antiplatelet therapy after acute coronary syndrome. N Engl J Med 2011;365:699-708. https://doi.org/10.1056/ NEJMoa1105819

11. Roffi M, Patrono C, Collet JP, Mueller C, Valgimigli M, Andreotti F, et al; ESC Scientific Document Group. 2015 ESC Guidelines for the management of acute coronary syndromes in patients presenting without persistent ST-segment elevation: Task Force for the Management of Acute Coronary Syndromes in Patients Presenting without Persistent ST-Segment Elevation of the European Society of Cardiology (ESC). Eur Heart J 2016;37:267-315. https://doi.org/ 10.1093/eurheartj/ehv320

12. Schömig A, Sarafoff N, Seyfarth M. Triple antithrombotic management after stent implantation: when and how? Heart 2009;95:1280-5. https://doi.org/10.1136/hrt.2008.160457

13. Dewilde WJ, Oirbans T, Verheugt FW, Kelder JC, De Smet BJ, Herrman JP, et al; WOEST study investigators. Use of clopidogrel with or without aspirin in patients taking oral anticoagulant therapy and undergoing percutaneous coronary intervention: an open-label, randomised, controlled trial. Lancet 2013;381:1107-15. https://doi.org/10.1016/S0140-6736(12)62177-1

14. Gibson CM, Mehran R, Bode C, Halperin J, Verheugt FW, Wildgoose P, et al. Prevention of bleeding in patients with atrial fibrillation undergoing $\mathrm{PCl}$. N Engl J Med 2016;375:2423-34. https://doi.org/10.1056/NEJMoa1611594

15. Cannon CP, Bhatt DL, Oldgren J, Lip GYH, Ellis SG, Kimura T, et al; RE-DUAL $\mathrm{PCI}$ Steering Committee and Investigators. Dual antithrombotic therapy with dabigatran after PCI in atrial fibrillation. N Engl J Med 2017;377:1513-24. https://doi.org/10.1056/NEJMoa1708454

16. Leon MB, Baim DS, Popma JJ, Gordon PC, Cutlip DE, Ho KK et al; Stent Anticoagulation Restenosis Study Investigators. A clinical trial comparing three antithrombotic-drug regimens after coronary-artery stenting. N Engl J Med 1998;339:1665-71. https://doi.org/10.1056/NEJM199812033392303

17. Bhatt DL, Eagle KA, Ohman EM, Hirsch AT, Goto S, Mahoney EM, et al; REACH Registry Investigators. Comparative determinants of 4-year cardiovascular event rates in stable outpatients at risk of or with atherothrombosis. JAMA 2010;304:1350-7. https://doi.org/10.1001/jama.2010.1322

18. Eikelboom JW, Connolly SJ, Bosch J, Dagenais GR, Hart RG, Shestakovska O, et al; COMPASS Investigators. Rivaroxaban with or without aspirin in stable cardiovascular disease. N Engl J Med 2017;377:1319-30. https://doi.org/ 10.1056/NEJMoa1709118

19. Lamberts M, Gislason GH, Lip GY, Lassen JF, Olesen JB, Mikkelsen AP, et al. Antiplatelet therapy for stable coronary artery disease in atrial fibrillation patients taking an oral anticoagulant: a nationwide cohort study. Circulation 2014:129:1577-85. https://doi.org/10.1161/CIRCULATIONAHA.113.004834 